\title{
Precision Forestry Using Airborne Hyperspectral Imaging Sensor
}

\author{
Kamaruzaman Jusoff \\ Tropical Forest Airborne Observatory (TropAIR) \\ Faculty of Forestry, Universiti Putra Malaysia \\ Serdang 43400, selangor, Malaysia \\ Tel: 60-3-8946-7176_E-mail: kjusoff@yahoo.com
}

The airborne mission campaign was funded by Aeroscan Precision (M) Sdn Bhd Project Office and Universiti Putra Malaysia (sponsoring information)

\begin{abstract}
Universiti Putra Malaysia in collaboration with a private company, Aeroscan Precision (M) Sdn Bhd based in UPM Serdang conducted a research and commercial applications of airborne hyperspectral sensing data in precision forestry. The UPM-APSB's AISA sensor was flown over a representative series of forested areas in Peninsular Malaysia from $12-20^{\text {th }}$. July 2004. It is a pushbroom imaging spectrometer recording remote sensing images over a large spectrum of wavelengths from the visible $(400 \mathrm{~nm})$ to near infrared $(1000 \mathrm{~nm})$. Images have a ground pixel size of $1 \mathrm{~m}$ by $1 \mathrm{~m}$ at a flight altitude of $1000 \mathrm{~m}$ a.s.1 and a constant flight speed of 120 knots. The ground validation segment of the projects was focused around hill/montane dipterocarps,. In order to characterize the properties and status of the forests, a number of images and field spectrum were developed. Prior to and after the flight, field spectral reflectance measurements using a handheld FieldSpec spectroradiometer were taken over the timber species of interest. The use of spectral unmixing methods for the discrimination of individual timber species image components leading to a more accurate identification of timber species, timber inventory and volume estimates were evaluated. The results imply that UPM-APSB airborne hyperspectral imaging technology would enable the development of a rapid forest resources assessment, especially in the sustainable forest management in Malaysia and other tropical countries.
\end{abstract}

Keywords: Airborne, Hyperspectral imaging, Precision forestry, Sustainable management

\section{Introduction}

Airborne hyperspectral imagers are powerful diagnostic tools for remote sensing. They will play an increasing worldwide role in forestry and other disciplines (Held and Hendrawan, 1996). A targeted imager will view smaller specific "target" areas selected by the user. A targeted hyperspectral imager operating from a low altitude flying aircraft will typically provide spatial and spectral resolutions in the order of $0.5-4 \mathrm{~m}$ and 5-20 nm, narrow, contiguous over the visible (VIS)-and-near-infrared, respectively.

An airborne hyperpsectral imager's ability to detect molecular absorption and particle scattering "signatures" of constituents is its defining advantage, compared with broadband multi spectral imaging sensors such as the Landsat TM, SPOT HRV, IKONOS and QuickBird. The finer spectral resolution of an airborne hyperpsectral imager, along with an appropriately high signal-to-noise ratio (SNR) in the wavelength of interest, allows detection and inferences of biological processes that are characterized by specific emission or absorption features. In many situations, an airborne hyperspectral imager can unambiguously identify surface constituents and their abundance, captures the unique spectra, or spectral signature of an object, which can then be used to identify and quantify the material(s) of which it is composed (Kamaruzaman, 2006a and 2006b). For vegetated targets, it has the effect of measuring the status of the targets such as within field variation and timber inventory for precision agriculture and forestry, respectively (Kamaruzaman and Dahlan, 2006a, 2006b and 2006c).

This paper therefore concerns a push-broom airborne hyperspectral imaging sensor technology for precision forestry applications using reflected solar radiation (400-900 um wavelength range) developed and operationalized by Aeroscan Precision (M) Sdn Bhd in collaboration with UPM's Forest Geospatial Information and Survey Laboratory (FGISL), Universiti Putra Malaysia, Serdang. 


\section{Materials and methods}

\subsection{Description and mounting of UPM-APSB's AISA Airborne Hyperspectral Imager}

UPM-APSB's AISA is a state-of-the-art fixed wing aircraft mounted commercial hyperspectral imager operationalized by Aeroscan Precision (M) Sdn Bhd. project office in Lebuh Silikon, in collaboration with Forest Geospatial Information \& Survey Lab (FGISL) of Universiti Putra Malaysia (Figure 1). It is designed to provide real time, frequent, repetitive, accurate and reliable pushbroom instrument that acquire images in 288 registered, contiguous narrow spectral bandpasses such that for each element it is possible to derive a complete reflectance spectrum. UPM-APSB hyperpsectral imager is a complete system that consists of a compact hyperspectral imager head, miniature GPS/INS sensor for precise positioning, data acquisition unit and Caligeo post-processing software. This small portable instrument, with a total weight of only 15 $\mathrm{kg}$ was mounted on an aluminium metal plate that is compatible with a standard aerial camera mount, available in any fixed wing aircraft such as that of a Pan Malaysia Air Transport (PMAT) Short SkyVan SC7 and/or a Sabah Air GAF Nomad N22B. Swath width is 360 pixels and field of view (FOV) in cross track direction $20^{\circ}$ which makes ground resolution from $1 \mathrm{~km}$ altitude approximately $1 \mathrm{~m}$ at a flight speed of $120 \mathrm{knots}(60 \mathrm{~m} / \mathrm{s})$. In addition, 20 pixels per swath for downwelling irradiance were acquired via a fiber optic irradiance sensor (FODIS) on the N22B aircraft. Accurate position information, necessary for image rectification is measured with Systron C-MIGITS II integrated GPS/INS unit, which includes 3-axial inertial measurement unit based on solid-state gyros, GPS receiver and real time Kalman filter. The effect of the aircraft such as the lateral roll is monitored using data from an onboard gyroscope. The advantage of UPM-APSB airborne hyperspectral imager over other airborne hyperspectral instruments is the flexibility in selecting the sensor's spatial and spectral resolution characteristics. Reflected light from the target below the aircraft is transmitted through a sensor lens and directed to a prism-grating-prism optical system, which splits the light into its component wavelength spectra. The refractive properties of the two opposing prisms allow for a linear projection of light onto the CCD two-dimensional array.

\section{$<<$ FIGURE $1>>$}

\subsection{Airborne data acquisition}

The calibration flight by UPM's FGISL/APSB took place from 18-19 February 2004 in Selangor using a SC-7 aircraft. The commercial operating flights on the GAF Nomad N22B twin engine aircraft for precision forestry data applications were successfully conducted from $12-20^{\text {th }}$. July 2006. The airborne data presented here were only part of that collected by the overall project. Over 20 flight lines were collected for the project corresponding to better than $90 \%$ of the proposed data acquisition (by area). Some data were not acquired because of the weather and other operational considerations. Data delivery over some selected Area of Interest (AOI's) was accomplished within 24 hours of completion of data acquisition.

\subsection{AISA data processing, field verifications and timber volume estimation}

UPM-APSB's imaging spectrometer was configured to measure 20 spectral bands. The data was first pre-processed by a Caligeo software (a plug-in of the latest ENvironment for Visualizing Images [ENVI]) version 4.0 for a calibrated, rectified and georeferenced image after performing the atmospheric, radiometric and geometric corrections. After pre-procesing, the data were processed digitally using ENVI version 4.0 which is a user-friendly to search for image spectral signatures, in addition to the geospatial capabilities, which result in an effective identification, visualization, spatial and spectral data reduction and management tool with integrated decision-making capabilities. The data were subjected to a minimum noise fraction transform, pixel purity index, n-dimension visualizer, identification, spectral angle mapper and mixture tuned matched filtering processing before getting the final output, AeroMap ${ }^{\mathrm{TM}}$. AeroMap ${ }^{\mathrm{TM}}$ ' $\mathrm{s}$ turn-around time is typically 24 hours from collected data to visualized information since a short-turn around time is required to keep data processing costs down and to achieve the maximum end user satisfaction.

After the individual tree species were identified, classified and mapped, the timber volume was estimated using the volume formulae and regression model shown in Figure 2.

$<$ FIGURE $2>>$

\section{Results and discussion}

Figure 3 demonstrated the usefulness of UPM-APSB's hyperspectral imager for precision forestry applications especially, individual tree species identification, classification and mapping that has benefited from the operationalization of UPM-APSB's AISA airborne hyperpsectral data.

\section{$<<$ FIGURE 3>>}

Airborne hyperspectral sensing has the potential to be useful for minimal impact harvesting since individual commercial tree species can be easily identified and mapped due to the different spectral "signatures" registered by different species (Figure 4). Upon combining this data with ground derived models that relate crown size to tree size (allometric relationships) for the various species in the project area, it was possible to derive the individual tree counts, average tree size by diameter size class, tree height and hence timber volume per hectare (Figures 5a and 5b). Using airborne 
hyperspectral imagery seems to improve timber inventory assessments, allowing for increased accuracy and detail of individual species for sustainable development and forest statistics. Measurements of forest chemistry in relation to tree health and stress is most likely possible due to spectral sample regions of healthy versus stressed timber trees was easily separated at the NIR spectrum using canopy reflectance.

$<<$ FIGURE 4 $>>$

$<<$ FIGURE 5a $>>$

$<<$ FIGURE $5 \mathrm{~b}>>$

Malaysia has both international and national reasons to assess the sustainable development of the nation's forests. Monitoring our forests is essential to preserving Malaysia's second largest revenue-generated industry next to petroleum. Also, there is a need to assess Malaysia's progress on international commitments eg. Kyoto Protocol products (forest inventory, afforestation, deforestation and reforestation) where their parameters can be derived from AeroMap ${ }^{\mathrm{TM}}$ products measured by UPM-APSB's AISA airborne hyperspectral imaging. The temporal components of these measures provide trends for policy makers and for sustainable forest managers.

\section{Conclusion}

UPM-APSB now has experience and expertise in the disciplines and technologies required for airborne hyperspectral imaging earth observation especially in precision forestry applications. Our data and product, AeroMap ${ }^{\mathrm{TM}}$ have demonstrated many useful precision forestry applications which can provide a potential and efficient means of managing and sustaining agriculture and forestry development with precise geospatial details of the targeted sites and very minimal ground control points (GCP's).

Geo-corrected data can be provided to clients/users as apparent reflectance to thematic base map and features extraction AeroMap ${ }^{\mathrm{TM}}$ products. Data, products and services from UPM-APSB's hyperspectral imager have being available for commercial purchase from Aeroscan Precision (M) Sdn Bhd. Project Office/FGISL at Lebuh Silikon, UPM. Utilizing this potential, Aeroscan Precision (M) Sdn Bhd/FGISL, UPM will organize similar missions upon request to interested clients in precision forestry and other applications. The current challenge is to intensify precision forestry applications development and to broaden the usage of airborne hyperspectral imaging data in Malaysia for forest inventory and reduced impact harvesting. This will entail the coordinated effort and support of the Malaysian government, industry and academia.

\section{References}

Held, A.A., and Hendrawan, D. (1996). The application of hyperspectral remote sensing technology for management of sensitive coastal zone areas. Paper presented at MAPIN VI, Ujung Padang, Indonesia. December 1996.

Kamaruzaman Jusoff. (2006a). UPM-APSB’s AISA Airborne Hyperspectral Imaging for Individual Species Mapping \& Timber Inventory In Bukit Lagong, F.R, Kepong, Selangor. Procs. KUSTEM $5^{\text {th }}$ Annual Seminar 2005 on Sustainability Science and Management: Meeting Challenges in Sustainability Agrotechnology (Sect.Conservation: AgroBiotechnology), 2-3 May, 2006, Primula Beach Resort, Kuala Trengganu, Trengganu, Malaysia.pp. 138-142.

Kamaruzaman Jusoff, (2006b). UPM-APSB's AISA Airborne Hyperspectral Imaging for Individual Mangrove Mapping in Port Klang. Procs. National Seminar on Science, Technology \& Social Science STSS2006, 30-31 May, 2006, Swiss Garden Resort \& Spa, Kuantan, Pahang, Malaysia.pp.751-759.

Kamaruzaman Jusoff and Dahlan Taha. (2006a). Preliminary Findings of UPM-APSB's Airborne Hyperspectral Imaging System for Gunung Stong State Forest Park Planning and Development. Procs. "Seminar Rancangan Pengurusan Taman Hutan Negeri Stong, Kelantan” (In Malay) (Eds. Hj. Kamaruzaman Jusoff \& Dato’ Hj. Dahlan Taha) $20^{\text {th }}$. March 2006 , Dewan Teratai, Kota Darul Naim, Kota Bharu, Kelantan. Pp.23-40.

Kamaruzaman Jusoff and Dahlan Taha. (2006b). Managing Biological Resources in the Best Managed State Park: Gunung Stong State Forest Park, Kelantan, Malaysia. An Invited Paper Presented at the $4^{\text {th }}$. WSEAS International Conference on Environment, Ecosystems \& Development (EED’06), November 20-22, 2006. Venice, Italy. 9p.

Kamaruzaman Jusoff and Dahlan Taha. (2006c) 


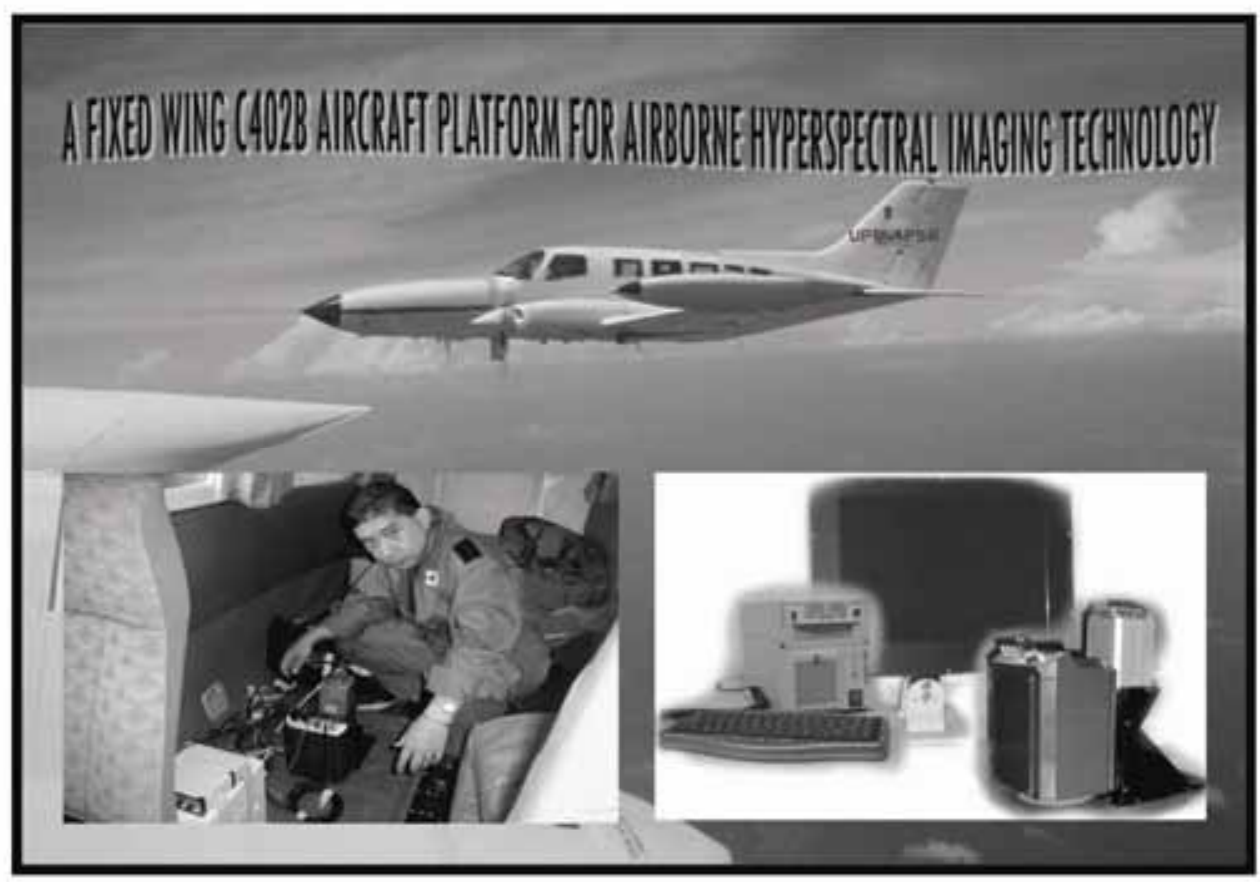

Figure 1. The airborne hyperpsectral imaging system kit and mounting of sensor on-board a fixed wing aircraft

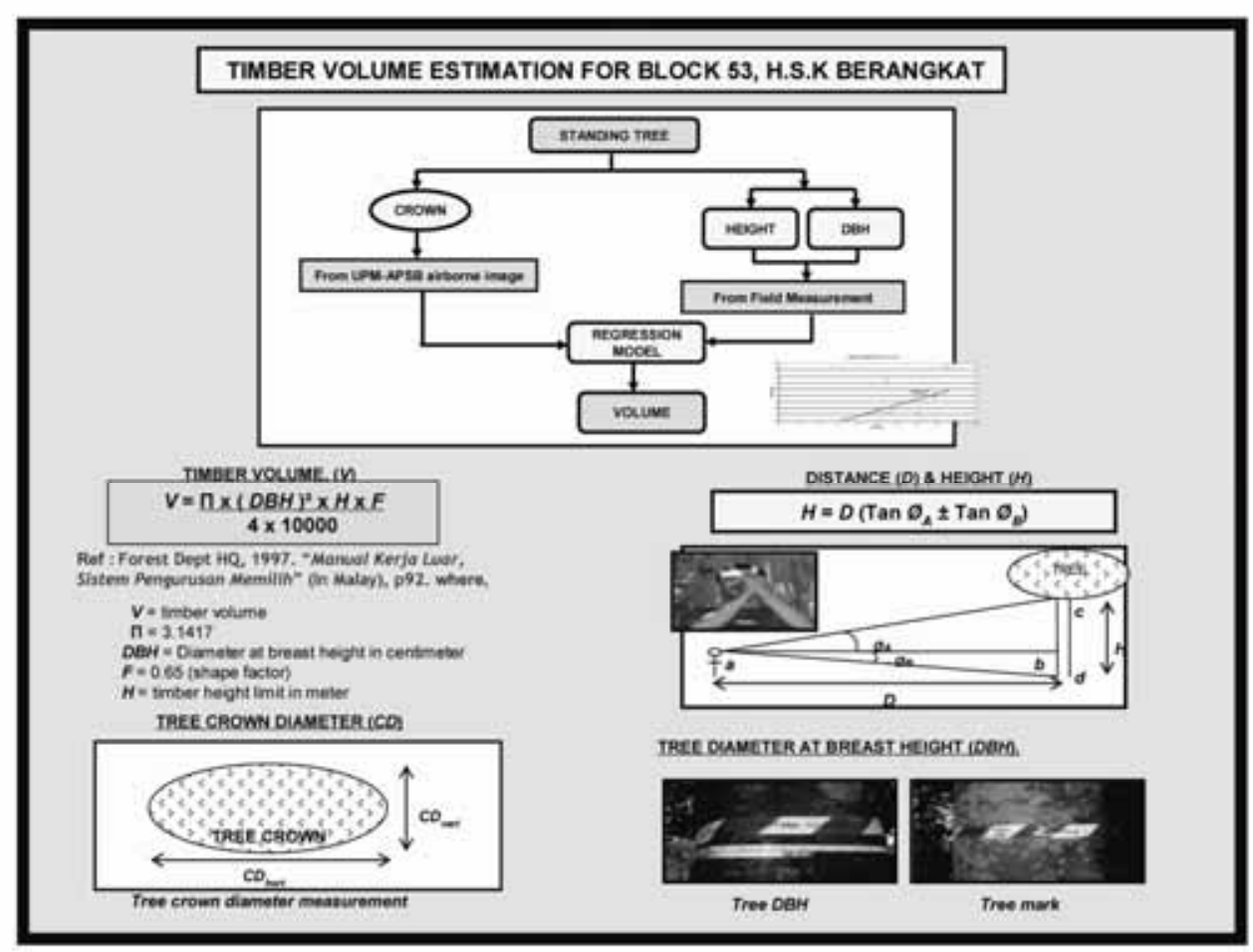

Figure 2. Estimating timber volume in Block 53 using the timber volume formulae and the derived regression model 


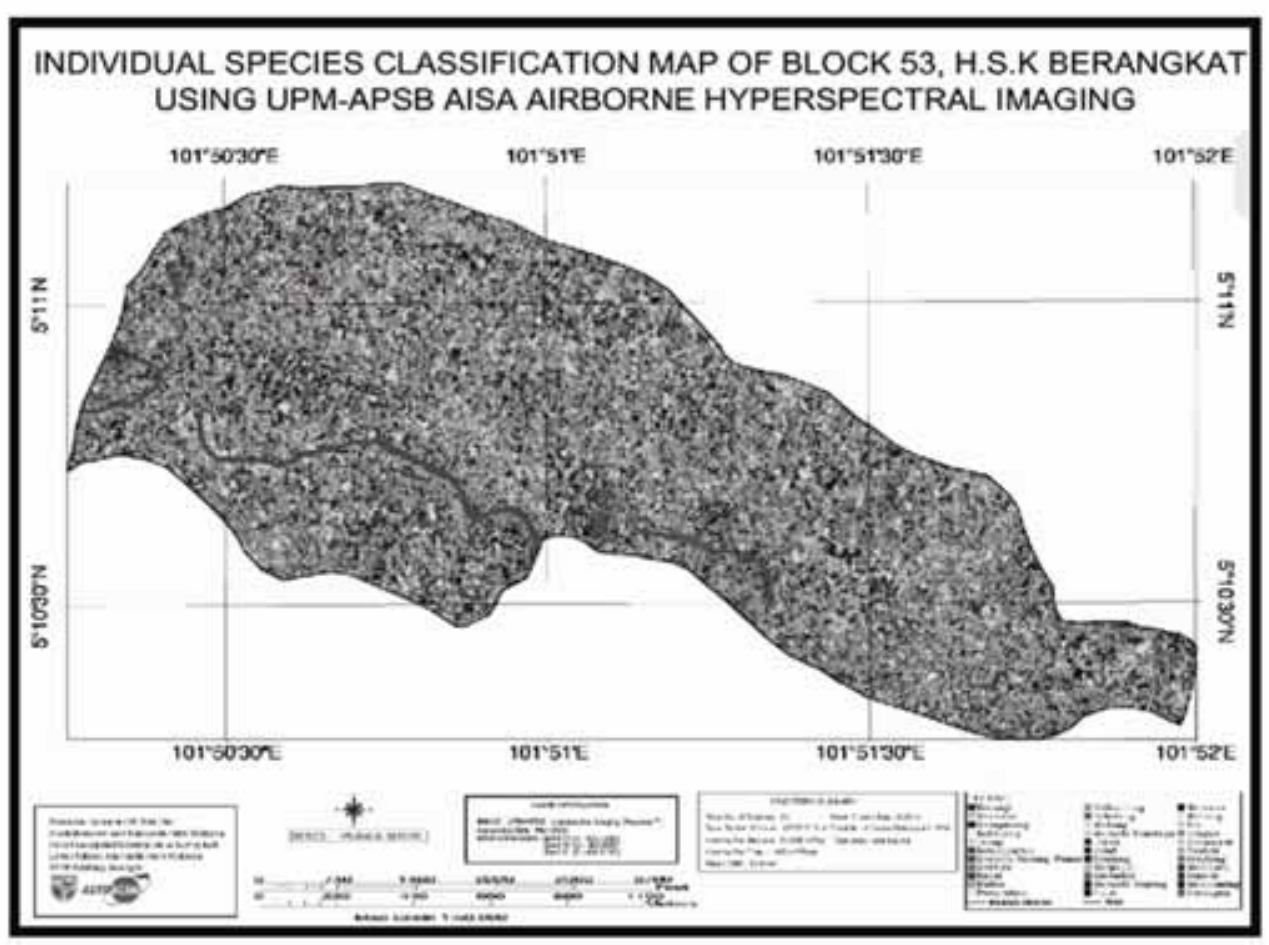

Figure 3. Identification, classification and mapping of individual tree species in a logging compartment, Block 53, Berangkat Permanent Forest Reserve

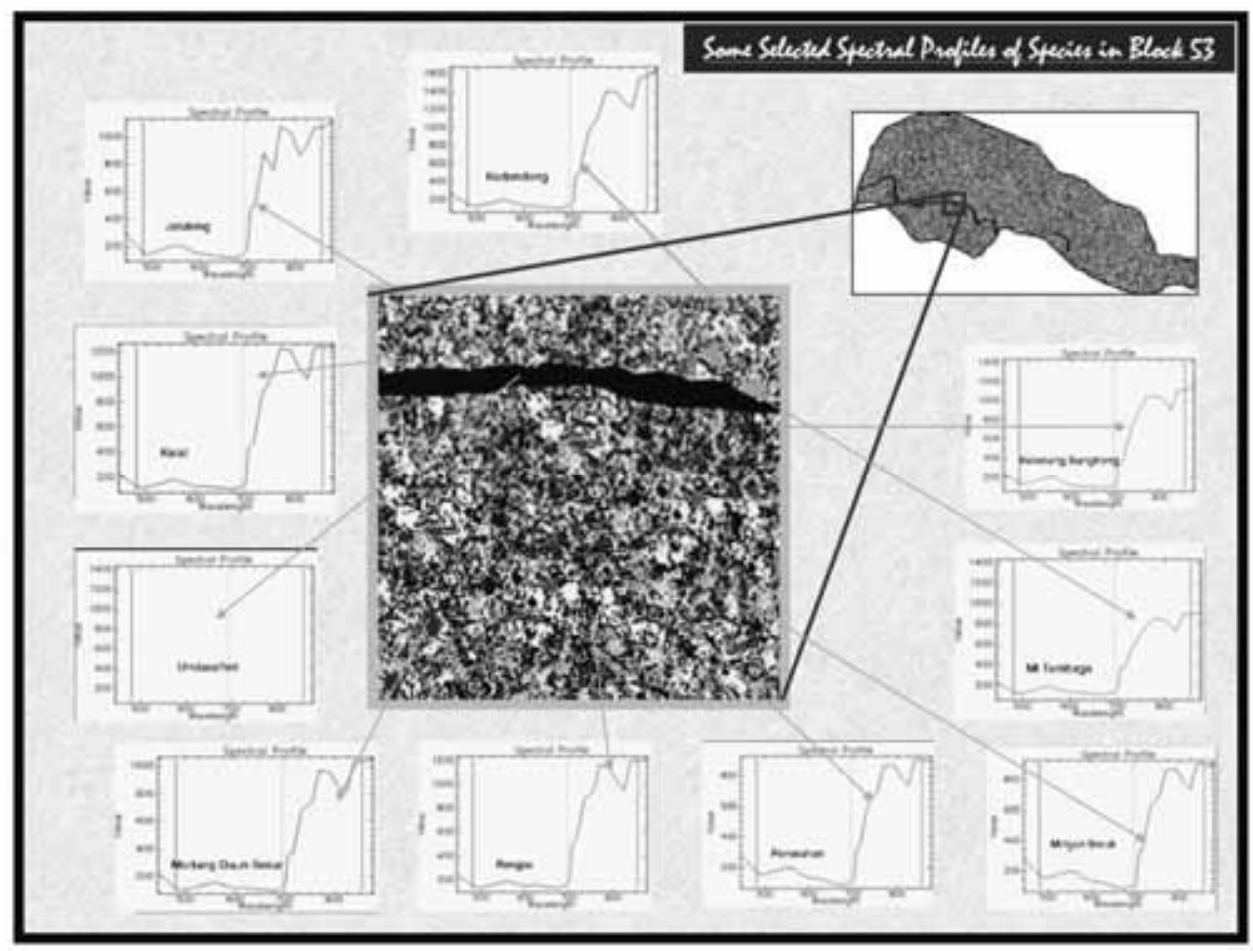

Figure 4. Mapping of individual timber species with different unique spectral libraries for precision forest inventory 


\begin{tabular}{|c|c|c|c|}
\hline \multicolumn{4}{|c|}{ Individual Species Ioformation of Black S3, Benenglat P.F.R } \\
\hline No & Type of Species & No of Tree Counts & Timber Volume, $\mathrm{m}^{3}$ \\
\hline 1 & Mahang & 3 & 2.34 \\
\hline 2 & Berangan & 14 & 136.92 \\
\hline 3 & Perah & 25 & 51.75 \\
\hline 4 & Tualang & 43 & 73.53 \\
\hline 5 & Nyatoh & 74 & 99.90 \\
\hline 6 & Mersawa Durian & 152 & 101.08 \\
\hline 7 & Kulim & 183 & 206.79 \\
\hline 8 & Merawan Siput Jantan & 237 & 457.41 \\
\hline 9 & Keledang & 293 & 5.86 \\
\hline 10 & Medang Daun Besar & 337 & 33.70 \\
\hline 11 & Ara Bertih & 355 & 170.40 \\
\hline 12 & Meranti Tembaga & 481 & $1,382.39$ \\
\hline 13 & Minyak Beruk & 315 & $3,244.50$ \\
\hline 14 & Medang & 234 & 348.66 \\
\hline 15 & Rengas & 504 & 549.36 \\
\hline 16 & Keledang Bangkong & 867 & 589.56 \\
\hline 17 & Kelat & 1,760 & $2,422.16$ \\
\hline 18 & Kedondong & 1,485 & $1,267.79$ \\
\hline III & Aectutine & 30 & 7.478.09: \\
\hline 20 & Penarahan & 596 & 426.14 \\
\hline 21 & Ara & 330 & 83.49 \\
\hline 22 & Nyatoh Taban & 2 & 4.28 \\
\hline
\end{tabular}

Figure 5a. Mapping of individual timber species with different unique spectral libraries for precision forest inventory

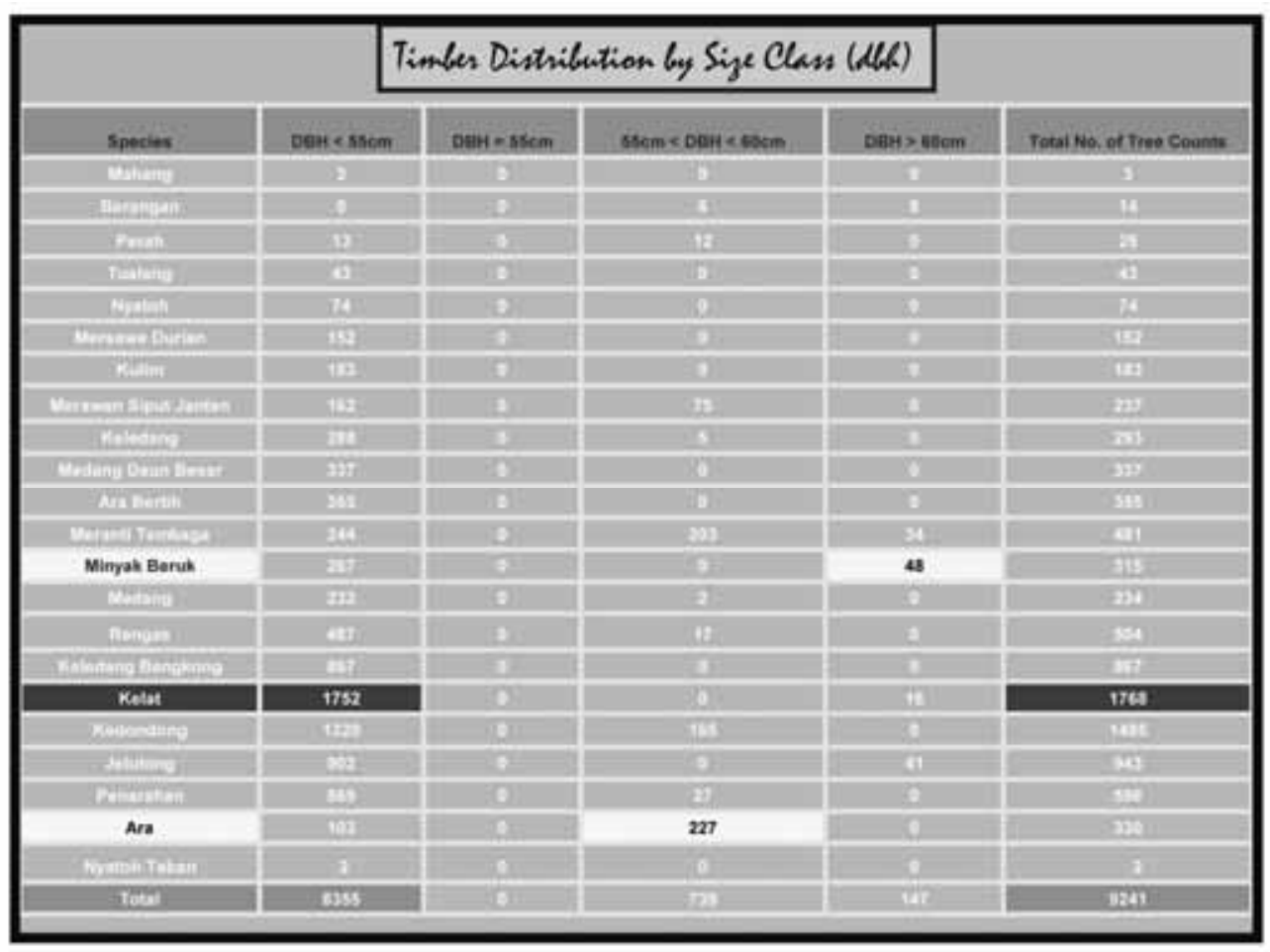

Figure 5b. Mapping of individual timber species with different unique spectral libraries for precision forest inventory. Managing Mountain Forest Resources of Gunung Stong, Kelantan using UPM-APSB's Airborne Hyperspectral Imaging. Paper Presented at the $3^{\text {rd }}$. Bangi World Conference on Environmental Management, 05-06 September 2006, Equatorial Hotel, Bangi, Selangor. 10p. 